\title{
The Rate of Water Loss in Relation to Internodes Position and Wood Maturity in Canes of the Grapevine
}

\author{
Florin $\mathrm{SALA}^{1^{*}}$, Alin DOBREI ${ }^{2}$ \\ ${ }^{1}$ Soil Science and Plant Nutrition, Banat University of Agricultural Sciences and Veterinary Medicine \\ "King Mochael I of Romania" from Timisoara, Calea Aradului 119, Romania \\ ${ }^{2}$ Horticulture, Banat University of Agricultural Sciences and Veterinary Medicine "King Michael I of \\ Romania" from Timisoara, Calea Aradului 119, Romania \\ *)Corresponding author, e-mail: florin_sala@usab-tm.ro
}

BulletinUASVM Horticulture 74(1) / 2017

Print ISSN 1843-5254, Electronic ISSN 1843-5394

DOI:10.15835/buasvmcn-hort:12636

\begin{abstract}
The purpose of study was to assess the rate of water loss from the canes of the grapevine of vines in relation to internodes position on vine chords and degree of wood maturity. The biological material was represented by grape cultivar Burgund mare, to which were analyzed individually all internodes distributed on the chord length (internodes number $\mathrm{IN}_{2-19}$ ). The rate of water loss and associated parameters (maximum rate of water loss - $\mathrm{RWL}_{\mathrm{Max}^{\prime}}$ total drying time $-\mathrm{T}$, time to achieve $\mathrm{RWL}_{\mathrm{Max}}-\mathrm{t}_{\mathrm{RWLMax}}$ ) were determined from the Burgund mare vine cultivar, in controlled condition. Parameters studied were associated with dry matter content (refractometric method), degree of maturity of the wood, and internodes positions on chord. RWL Max had higher values in the basal internodes $\left(\mathrm{IN}_{2}\right.$; $\left.\mathrm{RWL}_{\text {Max }}=0.252 \pm 0.005 \mathrm{~g} / \mathrm{min}\right)$ and lower in the apical internodes $\left(\mathrm{IN}_{17-19} ; \mathrm{RWL}_{\mathrm{Max}}=0.202 \pm 0.011 \mathrm{~g} / \mathrm{min}\right) . \mathrm{RWL}_{\text {Max }}$ distributions values, according to the position of internodes on cane was described by a third degree polynomial function, statistical safety $\left(\mathrm{R}^{2}=0.949, \mathrm{p}<0.01\right)$. Dry substance content in internodes (sugar) was correlated with the total time of water loss $\left(T ; R^{2}=0.945\right)$, the time to reach the maximum rate of water loss $\left(t_{\text {RWLMax }} ; R^{2}=0.855\right)$, and maximum rate of water loss $\left(\mathrm{RWL}_{\mathrm{Max}} ; \mathrm{R}^{2}=0.984\right)$.
\end{abstract}

Keywords: cane, rate of water loss, sugars, vine, wood maturation

\section{INTRODUCTION}

Water regimes in vines have been studied in relation to various biological, technological, and environmental factors. The specificity of vines cultivars in relation to water use (isohydric and anisohydric cultivars) determines different efficiency of water use, photosynthetic rates and variable tolerance to water stress (Rogiers et al., 2011; Hugalde and Vila, 2014). Aspects of hydration level and water loss from leave and shoots or stem on vines were studied in relation to the moment of harvesting, the degree of vine defoliation and time (Nicoletti et al., 2013).

Hochberg et al. (2013) based on their studies, found that isohidric vine cultivars presents higher photosynthetic efficiency and respiration rate in water stress conditions compared to anisohidrice cultivars. McCarthy et al. (2006) and Gerzon et al. (2015) have found that the "Shiraz" cultivar presented a more vigorous response to water deficit, which was manifested by a process of vegetative growth and defoliation slightly lower compared with "Grenache" cultivar. Analysis of anatomical architecture of the two vines cultivars, showed that "Grenache" have a larger diameter of conductive vessels (xylem), greater hydraulic conductivity and greater density of stomata than "Shiraz" (Schultz, 2003; Gerzon et al., 2015). It was considered that isohidric and anisohidric strategies may not be the result of distinct mechanisms, but 
rather a response, an adaptation of plants well defined in time. Soar et al. (2006) studying the two cultivars ("Shiraz" and "Grenache"), in terms of vapor pressure deficit (VPD), they found that the physiology of abscisic acid (ABA) is the key of contrasting responses between the two cultivars, being regarded as an genes expression in the leaves, but not in the roots.

Differentiated nutrition and water regime of the grapevine, on the constant background of soil and technological conditions, have led differentiated accumulation of dry matter and minerals in Burgund mare cultivar canes (Sala and Blidariu, 2012). Within some studies under irrigated conditions, Peacock (1998) found that low to moderate water stress level, achieved by controlled level of watering, had a positive effect for stopping the growth of shoots and maturation of wood on vines, and El-Gendy (2002) observed that excessive watering caused significant reduction in wood maturation in vine canes.

Developing methods for assessing the hydration status of plant and evapotranspiration level, it was considered to be necessary and useful for anticipating need for irrigation, in relationship to climatic conditions (Ferrari et al., 2015). They considered that a large part of understanding the processes of gas exchange and water were realized on the basis of foliar level studies, and extrapolating the results to the whole plant being difficult and not always accurate. In order to overcome this limitation, and increasing the safety of studies, they proposed and used a study chamber to measure the gas exchange in the whole plant under, high evapotranspiration conditions and extended period of time.

Canes maturation is an important aspect in the biological cycle of the vine, so for winter hardiness and canes quality for pruning fructifying for the maturation of buds or for the quality of the biological material for multiplying by cuttings (Rogiers et al., 2000). Wood maturation in canes, and consequently resistance to wintering and frost, and the viability of buds, has been associated with the specificity of biological material, being well known, varieties and local populations with of woodcanes ripening and high frost resistance, compared to others more sensitive, in similar vegetation conditions (Dobrei et al., 2015). Sugar content was the most frequently studied in grapes and other horticultural species, according to carbohydrate metabolism in plants (Wu et al., 2011), the relation of vine with soil, clime and technological factors (Jivan and Sala, 2014), production quality and wine processes (Dobrei et al., 2010, 2016; Blidariu et al., 2013), but equally important is the sugar content of the canes for the maturation of wood, winter hardiness, viability of buds and quality of chords for reproductive biological material (Rogiers et al., 2010; Smith et al., 2010).

In this study, evaluation of the loss of water was carried out under controlled conditions with a thermobalance in the infrared, in order to assess water loss parameters in correlation with the average content of dry substance (sugar) and the degree of maturation of the canes.

\section{MATERIAL AND METHOD}

The purpose of study was to assess the rate of water loss from the canes of vines in relation to internodes position on vine canes and degree of wood maturity.

The biological material was represented by Burgund mare vine cultivar. Samples were taken from the vine experimental plots of BUSAMV Timisoara. The canes were analyzed over the entire length (19 internodes; $\mathrm{IN}_{2-19}$ ), from each internode being extracted samples, which have been subjected to drying under controlled conditions. The rate of water loss, and associated parameters, was made with a infrared thermobalance (AXIS, ATS 60 Model), with an accuracy of $\pm 0.001 \mathrm{~g}$.

The rate of water loss and associated parameters (maximum rate of water loss - $\mathrm{RWL}_{\text {Max' }}$ total drying time - $\mathrm{T}$, time to achieve $\mathrm{RWL}_{\text {Max }}$ $t_{\text {RWLMax }}$ ) were determined from the Burgund mare vine cultivar, in controlled condition. Parameters studied were associated with dry matter content (determined by refractometry method), degree of maturity of the wood, and internodes positions on canes.

The experimental results were analyzed by the ANOVA test for assessing overall statistical data, in terms of safety. To assess the interdependence of the studied parameters was used correlation and regression analysis (Excel package, Office 2007 Suite). Grouping of internodes in relation to the studied parameters, based on Euclidean distances and of the degree of similarity of the results generated, was performed by clusters analysis with PAST software (Hammer et al., 2001). 
Tab. 1. Values of dry matter, moisture, drying time and the rate of water loss from the vine canes by grup of internodes in Burgund mare cultivar

\begin{tabular}{|c|c|c|c|c|c|c|}
\hline $\begin{array}{l}\text { Internodes } \\
\text { grup }\end{array}$ & $\begin{array}{l}\text { DM } \\
(\%) \\
\end{array}$ & $\begin{array}{c}\mathrm{M} \\
(\%) \\
\end{array}$ & $\begin{array}{c}\mathrm{T} \\
(\mathrm{s}) \\
\end{array}$ & $\begin{array}{l}\mathrm{RWL}_{\text {med }} \\
(\mathrm{g} / \mathrm{min})\end{array}$ & $\begin{array}{l}\mathrm{RWL}_{\mathrm{Max}} \\
(\mathrm{g} / \mathrm{min}) \\
\end{array}$ & $\begin{array}{l}\mathrm{t}_{\text {RWLMax }} \\
(\mathrm{s})\end{array}$ \\
\hline $\mathrm{IN}_{2}$ & $12.47 \pm 0.16$ & $45.32 \pm 0.28$ & $1060 \pm 19.03$ & $0.07375 \pm 0.0071$ & $0.252 \pm 0.005$ & $90 \pm 0.55$ \\
\hline $\mathrm{IN}_{3-4}$ & $12.35 \pm 0.13$ & $46.43 \pm 0.08$ & $1110 \pm 10.02$ & $0.06979 \pm 0.0062$ & $0.249 \pm 0.021$ & $80 \pm 0.43$ \\
\hline $\mathrm{IN}_{5-6}$ & $12.19 \pm 0.15$ & $46.51 \pm 0.32$ & $1065 \pm 5.04$ & $0.06579 \pm 0.0013$ & $0.249 \pm 0.009$ & $70 \pm 0.47$ \\
\hline $\mathrm{IN}_{7-16}$ & $11.91 \pm 0.09$ & $47.88 \pm 0.19$ & $977 \pm 12.83$ & $0.06479 \pm 0.0015$ & $0.233 \pm 0.006$ & $60 \pm 0.38$ \\
\hline IN $_{17-10}$ & $10.37 \pm 0.11$ & $49.38 \pm 0.31$ & $857 \pm 20.27$ & $0.05916 \pm 0.0028$ & $0.202 \pm 0.011$ & $50 \pm 0.26$ \\
\hline
\end{tabular}

Tab. 2. ANOVA test single factor

\begin{tabular}{ccccccc}
\hline Source of Variation & SS & Df & MS & F & P-value & F crit \\
\hline Between Groups & 13235063 & 4 & 3308766 & 2491.781 & $3.46 \mathrm{E}-87$ & 5.091526 \\
\hline Within Groups & 112869.1 & 85 & 1327.872 & & & \\
\hline Total & 13347932 & 89 & & & & \\
\hline
\end{tabular}

Alpha $=0.001$

Tab. 3. Matrix table of correlations between parameters studied in the internodes of vine canes

\begin{tabular}{ccccccc}
\hline & $\mathrm{DM}$ & $\mathrm{M}$ & $\mathrm{Tt}$ & $\mathrm{RWL}_{\mathrm{mad}}$ & $\mathrm{t}_{\mathrm{RWLMav}}$ & $\mathrm{RWL}_{\mathrm{Mav}}$ \\
\hline $\mathrm{DM}$ & & $6.53 \mathrm{E}-05$ & $9.38 \mathrm{E}-06$ & 0.016654 & 0.000183 & 0.002449 \\
\hline $\mathrm{M}$ & -0.801 & & $2.76 \mathrm{E}-09$ & 0.00816 & $1.75 \mathrm{E}-06$ & 0.006675 \\
\hline $\mathrm{Tt}$ & 0.847 & -0.947 & & 0.009432 & $2.90 \mathrm{E}-05$ & 0.002805 \\
\hline $\mathrm{RWL}_{\mathrm{med}}$ & 0.556 & -0.602 & 0.593 & & $8.13 \mathrm{E}-03$ & $6.29 \mathrm{E}-08$ \\
\hline $\mathrm{t}_{\mathrm{RWL} \text { Max }}$ & 0.770 & -0.877 & 0.822 & 0.603 & & 0.010376 \\
\hline $\mathrm{RWL}_{\mathrm{Max}}$ & 0.668 & -0.614 & 0.661 & 0.920 & 0.587 & \\
\hline
\end{tabular}

\section{RESULTS AND DISCUSSION}

Parameters for water loss from the vine canes (rate of water loss - RWL, the time to reach maximum rate of water loss $-t_{\mathrm{RWL}} \mathrm{Max}^{\prime}$ and the total time of drying - T) had specific variations in relation to the position internodes on canes. The degree of accumulation of dry matter sugarcane internodes, and thus, the woodcanes in basal positions had a better ripening compared to the woodcanes in middle and end position, experimental results being presented in Tab. 1 . ANOVA test indicated the existence of single factor variability in the experimental data, analyzed according to the internodes chord distribution $\left(\mathrm{IN}_{2}-\mathrm{IN}_{19}\right)$, Tab. 2 . Correlative statistical analysis of experimental data showed the existence of negative correlation of the parameters of rate of water loss with moisture and positive between them, with different level of significance, Tab. 3.

Time to achieve maximum rate of water loss $\left(\mathrm{t}_{\mathrm{RWLMax}}\right)$ in relation to the internodes position on vine canes, had higher values in basal internodes and lower values for apical internodes, distribution of this parameter being described by a third-degree polynomial function (equation 1), safely statistics $\left(R^{2}=0.949, p<0.01\right)$. Less time to achieve $\mathrm{RWL}_{\mathrm{Max}^{\prime}}$ expresses a quicker loss of water from plant material of the vine internodes studied.

$t_{\text {RWLMax }}=-0.0312 x^{3}+1.0182 x^{2}-11.154 x+100.75$

where: $x$ - internodes number ( $\mathrm{IN}=2$ to 19$)$.

Multiparameter analysis, based on Euclidean distances, facilitated internodes grouping depen- 


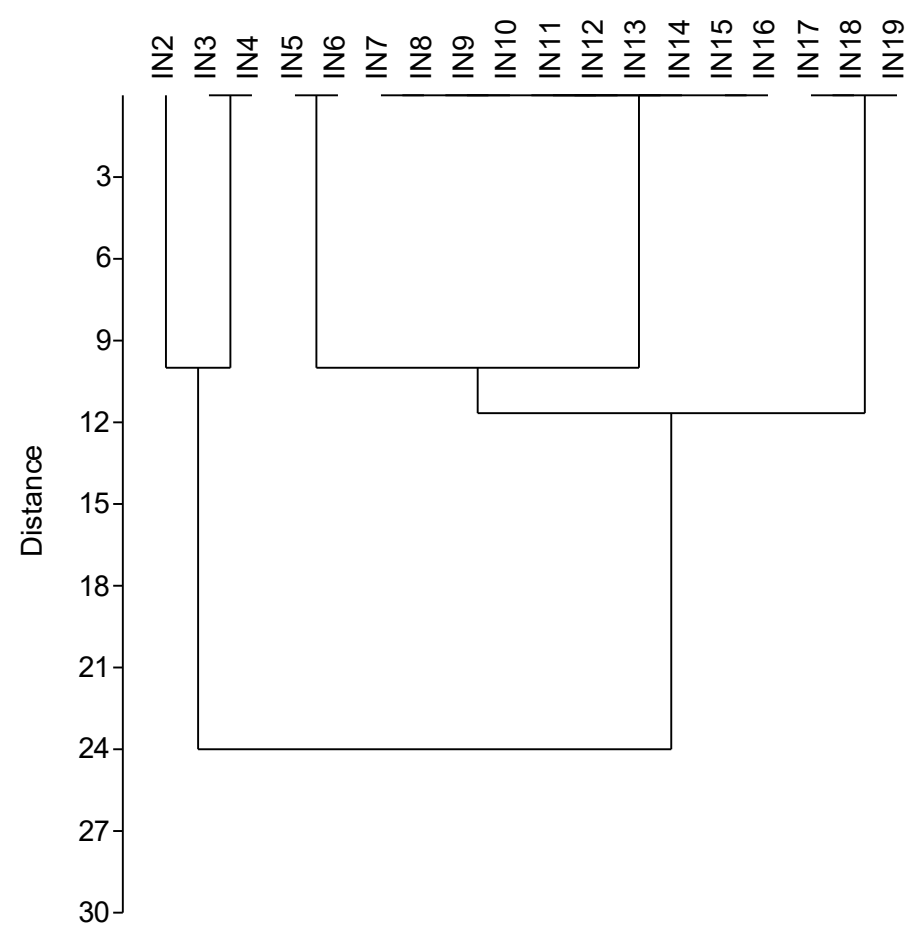

Fig. 1. Grouping clusters of vine internodes based on Euclidean distances, depending on the parameters $\mathrm{RWL}_{\mathrm{Max}}$ and $\mathrm{t}_{\mathrm{RWLMax}}$ (Burgund mare cultivar)

ding on the values of the parameters analyzed (RWLmax and $t_{\text {RWLMax }}$ ) in two clusters with five subclusters, Fig. 1, safely statistics (Cophenetic index $=0.906$ ).

For each group of internodes, of the five subclusters they were calculated functions that describe the rate of loss of water from the segments of the canes, depending on the time to achieve $\mathrm{RWL}_{\mathrm{Max}^{\prime}}$ equations (2) - (6).

For basal internodes, from the first two subclusters $\mathrm{C}_{1}\left(\mathrm{IN}_{2}\right)$ and $\mathrm{C}_{2}\left(\mathrm{IN}_{3}, \mathrm{IN}_{4}\right)$, the rate of water loss according to the time until the $\mathrm{RWL}_{\mathrm{Max}}$ has been described by polynomial functions of degree three in the statistical safe; $\mathrm{C}_{1}: \mathrm{R}^{2}=0.997$, $\mathrm{p}<0.01$, equation (2); $\mathrm{C}_{2}: \mathrm{R}^{2}=0.992, \mathrm{p}<0.001$, equation (3).

For internodes from subclusters $\mathrm{C}_{3}\left(\mathrm{IN}_{5}\right.$, $\left.I_{6}\right), C_{4}\left(I_{7}-I N_{16}\right)$ and $C_{5}\left(I_{17}-I_{19}\right)$, the rate of water loss in relation to time, until the $\mathrm{RWL}_{\mathrm{Max}^{\prime}}$ was described by polynomial functions of order four, also safely statistics; $\mathrm{C}_{3}: \mathrm{R}^{2}=0.998, \mathrm{p}<0.01$, equation (4); $\mathrm{C}_{4}: \mathrm{R}^{2}=0.998, \mathrm{p}<0.01$, equation (5); $\mathrm{C}_{5}: \mathrm{R}^{2}=0.996, \mathrm{p}<0.01$, equation (6).

Graphic distributions of curves, that express momentary values of $\mathrm{RWL}$, until the $\mathrm{RWL}_{\text {Max }}$ are represented in Fig. 2.

$y_{C 1}=-0.0001 x^{3}-0.0005 x^{2}+0.0469 x-0.0196$

$y_{C 2}=-0.0003 x^{3}+0.0008 x^{2}+0.0455 x-0.0225$

$y_{C 3}=0.0002 x^{4}-0.0043 x^{3}+0.0294 x^{2}-0.0221 x+0.028$

$y_{C 4}=0.0002 x^{4}-0.0038 x^{3}+0.0223 x^{2}+0.0004 x+0.008$

$y_{C 5}=0.0001 x^{4}-0.0021 x^{3}+0.0071 x^{2}+0.0428 x-0.0187$

where: $\mathrm{y}$ - rate of water loss (RWL) until reaching $\mathrm{RWL}_{\mathrm{Max}}$; $\mathrm{x}$ - time.

From analysis of the obtained functions, equations (2) - (6), and from graphically distribution (Fig. 2), was found a variable time to achieve $\mathrm{RWL}_{\mathrm{Max}}$ and different values of the intensity of this parameter.

The largest time to reach $\mathrm{RWL}_{\mathrm{Max}}$ was recorded at basal internode $\mathrm{IN}_{2}$ (90 seconds), afterwards 


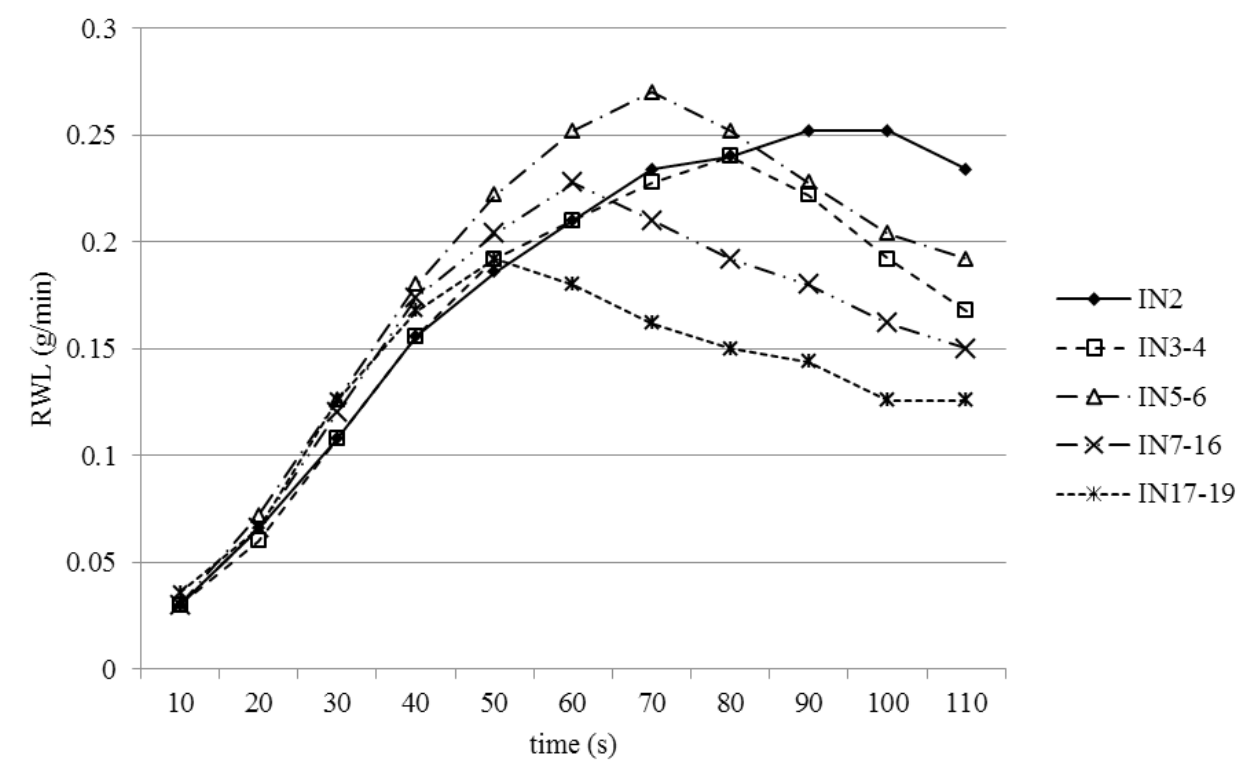

Fig. 2. Graphic distributions of $\mathrm{RWL}$ and $\mathrm{RWL}_{\mathrm{Max}}$ in relation with time

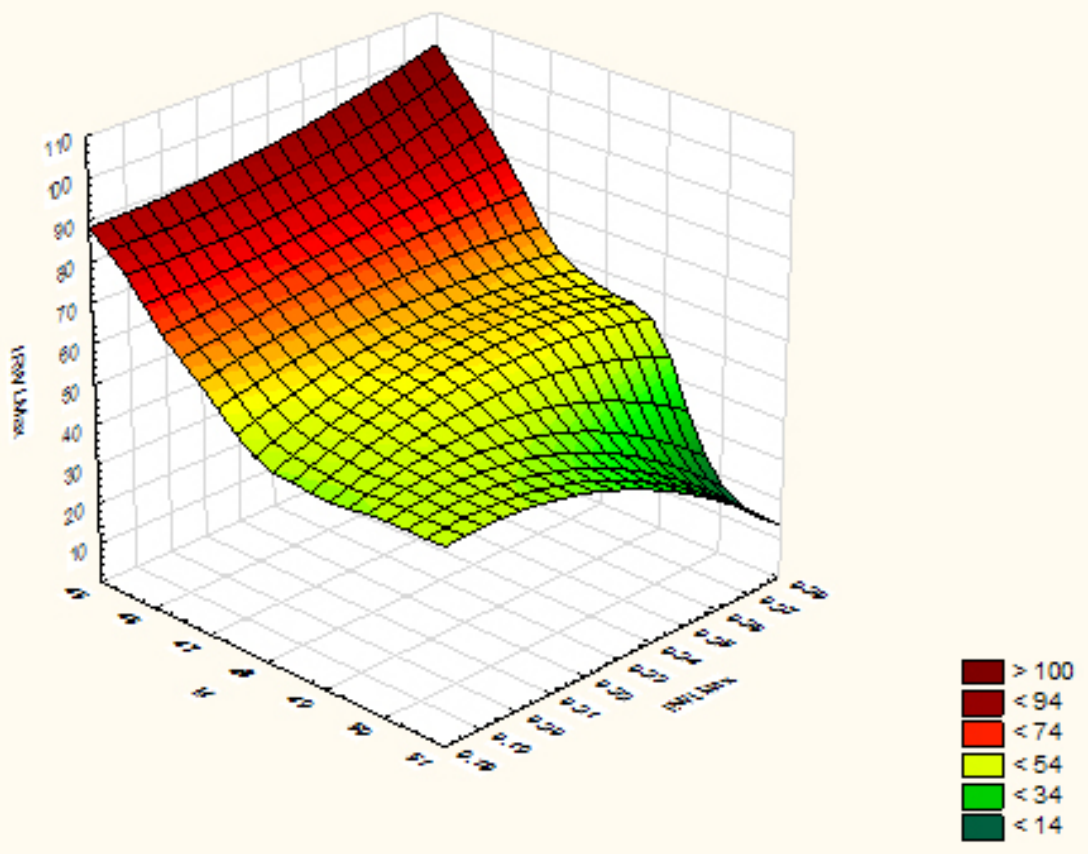

Fig. 3. 3D distribution of time to achieve $\mathrm{RWL}_{\mathrm{Max}^{\prime}}$ depending on the humidity and $\mathrm{RWL}_{\mathrm{Max}}$ values in vine canes, Burgund mare cultivar

at the internodes $\mathrm{IN}_{3}-\mathrm{IN}_{4}$ (80 seconds), and internodes $\mathrm{IN}_{5}-\mathrm{IN}_{6}$ (70 seconds).

At the internodes with the middle position on cane chord, $\mathrm{IN}_{7}-\mathrm{IN}_{16}, \mathrm{t}_{\mathrm{RWLMax}}$ parameter had 60-70 seconds, and the shortest time to reach $\mathrm{RWL}_{\mathrm{Max}}(50$ seconds) was recorded at terminals internodes $\left(\mathrm{IN}_{17}-\mathrm{IN}_{19}\right)$. 3D distribution of $\mathrm{t}_{\text {RWLMax }}$ parameter values is shown in Fig. 3.
Differentiated values for the total time of water loss $(\mathrm{T})$, the time to reach the maximum rate of water loss $\left(\mathrm{t}_{\mathrm{RWLMax}}\right)$, and the maximum rate of water loss $\left(\mathrm{RWL}_{\mathrm{Max}}\right)$, were correlated with the average content of dry matter (sugars) content from internodes, grouped into the five clusters.

Carbohydrate content had average values of: $12.47 \%$ in the second internode $\left(\mathrm{IN}_{2}\right) ; 12.35 \%$ in 
internodes 3 and $4\left(\mathrm{IN}_{3-4}\right) ; 12.19 \%$ by internodes 5 and $6\left(\mathrm{IN}_{5-6}\right) ; 11.91 \%$ by internodes 7 to $16\left(\mathrm{IN}_{7-16}\right)$ and $10.37 \%$ in the internodes 17 to $19\left(\operatorname{IN}_{17-19}\right)$.

Among the studied parameters (DM, M, $\mathrm{T}$, $R W L_{\text {Max }}, \mathrm{RWL}_{\text {med }}$, and $\mathrm{t}_{\mathrm{RWLMax}}$ ) were found interdependencies. High correlations were found between dry matter and moisture $(\mathrm{r}=-0.801)$, dry matter and total drying time, respectively $(\mathrm{r}=$ 0.847). Average correlations were found between dry matter and $t_{\text {RWLMax }}(r=0.770)$, and $R W L_{\text {Max }}$ respectively $(r=0.668)$. Low correlations were found between dry matter and $\mathrm{RWL}_{\text {med }}(\mathrm{r}=0.556)$. The specific parameters of weight loss rates were correlated with moisture, and based on direct and indirect relations of interdependence, the dry matter influenced water regime in vine canes.

The variation of carbohydrates in plants (leaves) in relation to water regime in plants, especially as an adaptation to water and temperature stress conditions, was also highlighted in other studies (David et al., 1998).

This indicates indirectly the maturation of wood and maturity and vigor of basal buds in relation to the apical, on the canes length. This has practical importance for frost resistance, cane pruning and crop regulation (Dobrei et al., 2015).

Another important aspect is related to the use of canes for vine propagation by classical techniques (by cuttings), by hydroponic or aeroponic techniques systems (Maroya et al., 2014) and by grafting. Basal internodes and buds have a higher vigor, followed by ones with middle placement on the canes length, the terminal buds having a weaker vigor.

Viability of the buds (from perspective of fruition cutting, and for reproductive material of vine), is also in relation with sugarcane content, content of minerals elements from chord, the degree of cane maturation, and indirect with the canes water content, elements influenced by variety, technology of crop and climatic conditions (Ciobanu et al., 2010; Smith et al., 2010; Sala and Blidariu, 2012; Dobrei et al., 2009, 2015).

The maturation of vine canes is an important aspect in the biological cycle of the vine, for winter resistance, and for quality of canes pruning, and for the quality of the biological material for propagation by cuttings (Rogiers et al., 2000).

This study showed the variation of parameters for weight loss in internodes of vine, Burgund mare cultivar, in relation to placing them on the chord length, values which were correlated with sugar content and degree of maturity of the wood in the canes.

\section{CONCLUSIONS}

The parameters, which expressing the water regime in vine cane $\left(\mathrm{RWL}_{\text {med }}, \mathrm{RWL}_{\text {Max }}, \mathrm{T}\right.$ and $t_{\text {RWLMax }}$ ) showed differentiated values in relation to internodes positioning on cane length.

Sugarcane content varied downwards from the base toward termination of chord, correlated by the regime of water loss parameters, and the degree of wood maturation.

Complex analysis of experimental data (multiparameter analysis based on Euclidean distances) facilitated grouping internodes function of the parameters analyzed ( $\mathrm{RWL}_{\mathrm{Max}}$ and $\left.\mathrm{t}_{\mathrm{RWLMax}}\right)$, in two clusters with five subclusters, safely statistics (Cophenetic index $=0.906$ ), basal internodes showing quality indices in relation to the life cycle of the vine, and practical interest for the vine propagation and maintenance of the plantation.

Acknowledgments. The authors thank to the staff of the Didactic and Experimental Station, Experimental and Research Center for Tree and Vine of the Banat University of Agricultural Sciences and Veterinary Medicine "King Michael I of Romania" from Timișoara, Romania, for facilitating the setup of the experimental field for this research.

\section{REFERENCES}

1. Blidariu C, Boldea M, Sala F (2013). Aspects of modeling regarding the contribution of nitrogen to the formation of grape yields. AIP Conf. Proc. 1558: 1575-1578.

2. Ciobanu F, Pop N, Farago M, Calugar A, Hodor D (2010). The influence of ecoclimatic conditions on wood maturation and bud's viability, at some varieties for quality wine, from Vineyard Tarnave. Bulletin USAMV Horticulture 67(1): 183-186.

3. David M, Coelho DM, Barrote I, Correia MJ (1998). Leaf age effects on photosynthetic activity and sugar accumulation in droughted and rewatered Lupinus albus plants. Aust J Plants Physiol 25: 299-306.

4. Dobrei A, Sala F, Mos V (2009). Local grapevine biotypes and varieties - a source for biodiversity, specificity and authenticity. Bulletin USAMV Horticulture 66(1): 260266.

5. Dobrei A, Poiana MA, Sala F, Ghita A, Gergen I (2010). Changes in the chromatic properties of red vines from Vitis vinifera L.cv. Merlot and Pinot Noir during the course of aging in bottle. J Food Agric Environ 8(2): 20-24. 
6. Dobrei A, Dobrei AG, Nistor E, Iordanescu OA, Sala F (2015). Local grapevine germplasm from Western of Romania - An alternative to climate change and source of typicity and authenticity. Agriculture and Agricultural Science Procedia 6: 124-131.

7. Dobrei A, Dobrei A, Posta G, Danci M, Nistor E, Camen D, Malaescu M, Sala F (2016). Research concerning the correlation between crop load, leaf area and grape yield in few grapevine varieties. Agriculture and Agricultural Science Procedia 10: 222-232.

8. El-Gendy RSS (2002). Utilization of evapotranspiration data of use in irrigation of Thompson and Flame Seedless grapevines. Ph. D. Thesis, Fac. Agric., Cairo Univ., Egypt.

9. Ferrari FN, Parera CA, Passera CB (2015). Whole plant open chamber to measure gas exchange on herbaceous plants. Chil J Agric Res 76(1): 93-99.

10. Gerzon E, Biton I, Yaniv Y, Zemach H, Netzer Y, Schwartz A, Fait A, Ben-Ari G (2015). Grapevine anatomy as a possible determinant of isohydric or anisohydric behavior. Am J Enol Vitic ajev.2015.14090.

11. Hammer $\varnothing$, Harper DAT, Ryan PD (2001). PAST: paleontological statisticssoftware package for education and data analysis. Palaeontol Electron 4(1): 1-9.

12. Hochberg U, Degu A, Fait A, Rachmilevitch S (2013). Near isohydric grapevine cultivar displays higher photosynthetic efficiency and photorespiration rates under drought stress as compared with near anisohydric grapevine cultivar. Physiol Plant 147(4): 443-452.

13. Hugalde IP, Vila HF (2014). Isohydric or anisohydric behaviour in grapevine..., a never-ending controversy? Revista de Investigaciones Agropecuarias 39(1): 1-7.

14. Jivan C, Sala F (2014). Relationship between tree nutritional status and apple quality. Hort. Sci. (Prague) 41(1): 1-9.

15. Maroya N, Balogun M, Asiedu R, Aighewi B, Kumar PL, Augusto J (2014). Yam propagation using 'aeroponics' technology. Annu Res Rev Biol 4(24): 3894-3903.

16. McCarthy MG, Loveys B, Penrose AB, Maffei SM, Speirs J, Soar CJ (2006). Grape vine varieties Shiraz and Grenache differ in their stomatal response to VPD: apparent links with ABA physiology and gene expression in leaf tissue. Aust J Grape Wine Res 12(1): 2-12.

17. Nicoletti I, Bellincontro A, De Rossi A, De Sanctis F, Tiberi D, Pietromarchi P, Botondi R, Corradini D, Mencarelli F (2013). Postharvest dehydration of Nebbiolo grapes grown at altitude is affected by time of defoliation. Aust J Grape Wine Res 19(3): 358-368.

18. Peacock B (1998). Water management for grapevines. The University of California Cooperative Extension (UCCE), Tulare County Publication IG9-98, pp: 10.

19. Popescu D, Pop A, Iliescu M (2010). Influence of thinning grapes on vine block wintering, in five grape varieties for red wines, cultivated in NW Romania. Bulletin USAMV Horticulture 69(1): 1-6.

20. Rogiers SY, Keller M, Holzapfel BP, Virgona JM (2000). Accumulation of potassium and calcium by ripening berries on field vines of Vitis vinifera (L) cv. Shiraz. Aust J Grape Wine Res 6(3): 240-243.

21. Rogiers SY, Greer DH, Hutton RJ, Clarke SJ (2011). Transpiration efficiency of the grapevine cv. Semillon is tied to VPD in warm climates. Ann Appl Biol 158(1): 106114.

22. Sala F, Blidariu C (2012). Macro- and micronutrient content in grapevine cordons under the influence of organic and mineral fertilization. Bulletin USAMV CN Horticulture 69(1): 317- 324.

23. Schultz HR (2003). Differences in hydraulic architecture account for nearisohydric and anisohydric behaviour of two field-grown Vitis Vinifera L. cultivars during drought. Plant Cell Environ 26: 1393-1405.

24. Soar CJ, Speirs J, Maffei SM, Penrose AB, McCarthy MG, Loveys BR (2006). Grape vine varieties Shiraz and Grenache differ in their stomatal response to VPD: apparent links with ABA physiology and gene expression in leaf tissue. Aust J Grape Wine Res 12(1): 2-12.

25. Wu B-H, Liu H-F, Guan L, Fan P-G, Li S-H (2011). Carbohydrate metabolism in grape cultivars that differ in sucrose accumulation. Vitis 50(2): 51-57. 